\title{
ĐÁNH GIÁ RỦI RO TRONG HOẠT ĐộNG CHUỖI CUNG ỨNG: TRƯƠNG HỢP CÔNG TY TNHH SYNTHOMER VIẸTT NAM
}

\author{
NGUYỄN QUANG VINH ${ }^{1}$, MAI THI KIM HUYỀN ${ }^{2}$ \\ ${ }^{1}$ Trường Đại học Công nghiệp thành phố Hồ Chí Minh ${ }^{1}$ \\ ${ }^{2}$ Công ty TNHH Synthomer Việt Nam \\ huyen.mai@synthomer.com_nguyenquangvinh@iuh.edu.vn
}

Tóm tắt. Rủi ro có thể xảy ra ở một điểm nào đó trong chuỗi cung ứng sẽ gây ảnh hưởng lớn đến doanh nghiệp nếu như doanh nghiệp không thể kiểm soát tốt. Công ty TNHH Synthomer Việt Nam hiện cũng đang rất quan tâm đến vấn đề này trong quản trị chuỗi cung ứng của mình. Đánh giá các rủi ro tiềm năng cùng các tác động để từ đó đưa ra một số hàm ý quản trị nhằm giảm thiểu, kiểm soát và xử lý tốt các rủi ro ưu tiên là mục tiêu của nghiên cứu này. Kỹ thuật phân tích tác động và hình thức sai lỗi FMEA được xử dụng kết hợp với phỏng vấn 10 chuyên gia đưa đến kết quả 8 rủi ro được xác định cần phải được ưu tiên xử lý trước so với 22 rủi ro còn lại kèm theo các hàm ý quản trị tương ứng giúp Synthomer Việt Nam cải thiện hiệu quả chuỗi cung ứng của Công ty.

Từ khóa. Quản trị rủi ro, chuỗi cung ứng, Synthomer Việt Nam

\section{RISK ASSESSMENT IN SUPPLY CHAIN: THE CASE OF SYNTHOME VIETNAM}

\begin{abstract}
Risks could occur at anytime in a supply chain, causing great effect to an enterprise where risk controls are not good enough. Synthomer Vietnam limited company is very interested in this matter concerning its supply chain. Assessing petential risks, effects, and solutions given for priority risks are objectives of this research. The technique of Failure Mode \& Effects Analysis, combining with expert indepth interview resulted to 8 potential risks out of the rest of 22 and the 8 correspongdingly priority solutions are suggested to help Synthomer Vietnam improve its supply chain management.
\end{abstract}

Keywords. Risk management, supply chain management, Synthomer Vietnam

\section{1 ĐẶT VẤN ĐỀ}

Hoạt động sản xuất và thương mại hóa toàn cầu hiện nay đã tạo điều kiện cho các doanh nghiệp nắm bắt cơ hội hợp tác với các đối tác bên ngoài doanh nghiệp nhằm nâng cao hiệu quả hoạt động sản xuất kinh doanh. Các doanh nghiệp không còn hoạt động độc lập mà kết hợp với nhau tạo ra mạng lưới chuỗi cung ứng ngày càng phát triển. Việc vận dụng, quản trị tốt chuỗi cung ứng đã giúp cho các doanh nghiệp có được lợi thế cạnh tranh trên thị trường trong và ngoài nước. Cạnh tranh toàn cầu đang ngày càng trở nên khốc liệt hơn cùng với sự phát triển ngày càng phức tạp của chuỗi cung ứng. Số lượng các doanh nghiệp không có được chuỗi cung ứng hoạt động hiệu quả ngày càng tang mà lý do chủ yếu xuất phát từ các rủi ro trong hoạt động của chuỗi cung ứng [1]. Bên cạnh đó, các thảm họa thiên nhiên bất ngờ (như trận động đất và sóng thần xảy ra ở Nhật Bản hồi tháng 3 năm 2011) cũng góp phần gây ảnh hưởng nghiêm trọng đến nhiều doanh nghiệp. Các cuộc chiến thương mại giữa một số cường quốc kinh tế trên thế giới gần đây cũng đã cho thấy khả năng xảy ra lớn của các rủi ro trong hoạt động kinh doanh toàn cầu. Trong những tình huống nghiêm trọng, rủi ro xảy ra ở một điểm nào đó trong chuỗi cung ứng có thể gây tổn thất lớn cho doanh nghiệp, thậm chí dẫn đến phá sản. Toàn cầu hóa đã mang lại nhiều lợi thế và hiệu quả hoạt động cho chuỗi cung ứng đồng thời cũng tạo ra nhiều nguy cơ rủi ro tiềm ẩn. Từ thực tế trên, trả lời câu hỏi làm thế nào để ngăn ngừa, giảm thiểu rủi ro trong quá trình từ tìm kiếm nguồn nguyên liệu, sản xuất và phân phối sản phẩm đến tay khách hàng là một trong những thách thức lớn đối với các doanh nghiệp tại Việt Nam khi mà "sự tham gia của các doanh nghiệp Việt Nam trong mạng lưới sản xuất chuỗi giá trị toàn cầu còn thấp so với các nền kinh tế có quy mô tương tự trong khu vực Đông Nam Á" [2]. Điều này gây không ít khó khăn lẫn rủi ro cho các công ty khi hợp tác với nhau trong chuỗi cung ứng tại Việt Nam. 
Là một doanh nghiệp FDI tại Việt Nam, chuyên sản xuất, kinh doanh nguyên phụ liệu cho ngành sơn, nguyên liệu keo dán trong ngành bao bì giấy và keo dán cho ngành gỗ công nghiệp, Công ty TNHH Synthomer Việt Nam (Synthomer Việt Nam) cũng đã và đang gặp phải những khó khăn trong hoạt động sản xuất kinh doanh do nhu cầu của thị trường trong ngành sơn xây dựng sụt giảm, một hệ quả của sự đóng băng thị trường bất động sản trong những năm vừa qua tại Việt Nam. Để có thể vượt qua giai đoạn khó khăn này và tiếp tục phát triển trong thời gian tới, ban giám đốc Công ty đã đề ra những phương án nhằm giảm thiểu chi phí đầu vào, trong đó có yêu cầu các phòng ban trong Công ty không để phát sinh các chi phí do các rủi ro không lường trước được trong quá trình hoạt động sản xuất kinh doanh gây ra. Đầu năm 2015, ông Calum Maclean - CEO của tập đoàn Synthomer- đã ban hành chính sách "Risk management" (Phụ lục 01), theo đó, Tập đoàn cam kết xem quản trị rủi ro hiệu quả là một phần không thể thiếu trong hoạt động sản xuất kinh doanh của mình. Đầu năm 2016, tập đoàn đã triển khai kế hoạch chuyển đổi từ ISO 9001:2008 lên ISO 9001:2015, dự kiến chính thức áp dụng phiên bản mới vào cuối năm 2018. ISO 9001:2015 là một phiên bản hệ thống quản lý chất lượng ISO 9001 có tư duy dựa trên quản lý rủi ro. Là một công ty con trực thuộc tập đoàn Synthomer, Synthomer Việt Nam cũng phải tuân thủ chính sách quản trị rủi ro của Tập đoàn cũng như chuẩn bị sẵn sàng để hoàn thành công tác chuyển đổi phiên bản mới của ISO 9001 theo đúng kế hoạch Tập đoàn đã đề ra. Đây cũng chính là lý do dẫn đến nghiên cứu "Đánh giá rủi ro trong hoạt động chuỗi cung ứng tại Công ty trách nhiệm hữu hạn Synthomer Việt Nam" được thực hiện với mục đích giúp cải thiện chất lượng công tác quản trị chuỗi cung ứng của Synthomer Việt Nam ở hiện tại và trong tương lai. Các câu hỏi như: 1) những rủi ro nào có thể xảy ra trong hoạt động chuỗi cung ứng của Synthomer Việt Nam? 2) tần suất, độ nghiêm trọng, khả năng phát hiện và độ lớn các rủi ro này như thế nào? và 3) các hàm ý quản trị nào cho Synthomer Việt Nam để Công ty có thể kiểm soát, giảm thiểu, và xử lý tốt các rủi ro ưu tiên trong hoạt động chuỗi cung ứng một cách có hiệu quả hơn sẽ được trả lời qua nghiên cứu này.

\section{PHƯONG PHÁP NGHIÊN CÚU}

Dựa trên mô hình quá trình quản lý rủi ro được giới thiệu trong Tiêu chuẩn quốc gia TCVN ISO/IEC 31010:2013 (IEC/ISO 31010:2009) về Quản lý rủi ro - Kỹ thuật đánh giá rủi ro [3], nghiên cứu đã thực hiện phỏng vấn 9 nhà quản lý cấp cao của Tập đoàn Synthomer (Tổng giám đốc Công ty Synthomer Việt Nam, Quản lý Chuỗi cung ứng tập đoàn Synthomer khu vực Đông Nam Á, Quản lý chất lượng tập đoàn Synthomer khu vực Đông Nam Á, Giám đốc tài chính, Giám đốc sản xuất, Trưởng ban quản lý chất lượng, chuyên viên an toàn, chuyên viên mua hàng, chuyên viên chăm sóc khách hàng và điều phối, giám sát kho) cùng 1 chuyên gia về quản trị chuỗi cung ứng và quản trị rủi ro khác (Giám đốc tư vấn rủi ro Tập đoàn PricewaterhouseCoopers Việt Nam). Liên quan đến thực trạng hoạt động chuỗi cung ứng tại Synthomer Việt Nam, các dữ liệu có sẵn từ Công ty (các báo cáo tài chính, tồn kho, khảo sát sự hài lòng khách hàng, khiếu nại khách hàng và các tài liệu khác) được thu thập, chọn lọc, và tổng hợp để mô tả thực trạng chuỗi cung ứng và các rủi ro có liên quan. Với kinh nghiệm trực tiếp tham gia vào quản lý hoạt động chuỗi cung ứng, các chuyên gia hiểu rõ về các rủi ro và cung cấp các đánh giá định lượng chính xác về các rủi ro Synthomer Việt Nam đã, đang và sẽ gặp phải.

Bảng 1: Các buớc thục hiện trong phân tích tác động và hình thức sai lỗi (FMEA)

\begin{tabular}{|c|l|}
\hline Bước 1 & Xem xét quá trình hay sản phẩm \\
\hline Bước 2 & Động não để tìm ra các sai lỗi tiềm ẩn \\
\hline Bước 3 & Liệt kê các tác động tiềm ẩn cho từng sai lỗi \\
\hline Bước 4 & Xác định mức độ nghiêm trọng của từng tác động \\
\hline Bước 5 & Xác định tần suất xảy ra của các sai lỗi \\
\hline Bước 6 & Xác định khả năng phát hiện ra các sai lỗi và/hoặc các tác động \\
\hline Bước 7 & Tính toán hệ số rủi ro (RSV), và hệ số ưu tiên rủi ro (RPN) cho từng sai lỗi \\
\hline Bước 8 & Tính toán tìm ra các sai lỗi ưu tiên xử và đưa ra các hành động ngăn ngừa \\
\hline Bước 9 & Hành động để giảm thiểu hoặc loại bỏ các sai lỗi \\
\hline Bước 10 & Tính toán lại RPN sau khi thực hiện hành động giảm thiểu, ngăn ngừa \\
\hline
\end{tabular}

(Nguồn: McDermott và các cộng sự, 2008) 
Dữ liệu phỏng vấn từ các nhà quản lý cấp cao và chuyên gia được ghi nhận vào "Potential FMEA Analysis worksheet" và được sử dụng để đánh giá và phân tích các rủi ro theo Phương pháp phân tích tác động và hình thức sai lỗi FMEA (Failure Mode Effect Analysis) nhằm định lượng khả năng xuất hiện, mức độ nghiêm trọng và khả năng phát hiện rủi ro cũng như tiến hành xác định hệ số rủi ro RSV (Risk Score Value) và hệ số ưu tiên rủi ro RPN (Risk Priority Number) [4]. Biểu đồ Pareto cho RSV, RPN được thiết lập để tìm ra $20 \%$ rủi ro cần ưu tiên giải quyết với công thức RSV = Occurence $x$ Severity; và RPN $=$ Occurence $\mathrm{x}$ Seveity $\mathrm{x}$ Detection. Cuối cùng, sơ đồ Scatter kết hợp với kết quả từ biểu đồ Pareto được sử dụng để xếp hạng rủi ro và thứ tự ưu tiên giải quyết của từng rủi ro. Nghiên cứu này sử dụng bộ thang đo của Palaniappan [6], trong đó, thấp nhất là 1 điểm và cao nhất là 10 điểm.

Bảng 2: Các thang đo dụa theo bộ thang đo của Palaniappan (2014)

\begin{tabular}{|c|c|c|c|}
\hline & Khả năng xuất hiện & Diễn giải & $\begin{array}{c}\text { Mức } \\
\text { độ }\end{array}$ \\
\hline \multirow{7}{*}{$\begin{array}{l}\text { Thang đo khả } \\
\text { năng xuất hiện }\end{array}$} & Chắc chắn xảy ra & Rủi ro xảy ra ít nhất 1 lần trong ngày & 10 \\
\hline & Thường xuyên xảy ra & $\begin{array}{l}\text { Có thể đoán được rủi ro sẽ xảy ra hoặc rủi ro xảy ra } 3 \text { hoặc } 4 \\
\text { ngày } 1 \text { lần }\end{array}$ & 9 \\
\hline & Khả năng xảy ra cao & Rủi ro xảy ra thường xuyên hoặc 1 tuần 1 lần & $\begin{array}{l}8 \\
7\end{array}$ \\
\hline & Có thể xảy ra & Rủi ro thỉnh thoảng xảy ra 1 tháng 1 lần & $\begin{array}{l}6 \\
5\end{array}$ \\
\hline & Khả năng thấp & Rủi ro thỉnh thoảng xảy ra hoặc xảy ra khoảng 3 tháng 1 lần & $\begin{array}{l}4 \\
3 \\
\end{array}$ \\
\hline & Hiếm khi xảy ra & Rất hiếm khi xảy ra rủi ro hoặc xảy ra khoảng mỗi năm 1 lần & 2 \\
\hline & Rất hiếm xảy ra & $\begin{array}{l}\text { Hầu như không xảy ra, không ai còn nhớ lần cuối cùng rủi ro } \\
\text { xảy ra khi nào }\end{array}$ & 1 \\
\hline \multirow{7}{*}{$\begin{array}{l}\text { Thang đo mức } \\
\text { độ nghiêm } \\
\text { trọng }\end{array}$} & Rất nghiêm trọng & Rủi ro gây tổn thất cho khách hàng. & 10 \\
\hline & Nghiêm trọng & Rủi ro gây đình trệ hoạt động & 9 \\
\hline & Khá nghiêm trọng & $\begin{array}{l}\text { Rủi ro gây ảnh hưởng thấp đến trung bình các hoạt động và } \\
\text { làm cho nhiều khách hàng không hài lòng. }\end{array}$ & $\begin{array}{l}8 \\
7\end{array}$ \\
\hline & Nghiêm trọng & $\begin{array}{l}\text { Rủi ro gây đình trệ hoạt động ở mức độ thấp và làm cho } 1 \text { số } \\
\text { khách hàng không hài lòng }\end{array}$ & $\begin{array}{l}6 \\
5\end{array}$ \\
\hline & Hơi nghiêm trọng & $\begin{array}{l}\text { Rủi ro gây rất ít hoặc không đình trệ hoạt động nhưng có thể } \\
\text { gây khách hàng phiền lòng }\end{array}$ & $\begin{array}{l}4 \\
3\end{array}$ \\
\hline & Ít nghiêm trọng & $\begin{array}{l}\text { Rủi ro không gây đình trệ hoạt động và khách hàng không } \\
\text { biết rủi ro xảy ra. }\end{array}$ & 2 \\
\hline & Không nghiêm trọng & $\begin{array}{l}\text { Rủi ro không gây đình trệ hoạt động và không ảnh hưởng } \\
\text { đến hệ thống }\end{array}$ & 1 \\
\hline \multirow{7}{*}{$\begin{array}{l}\text { Thang đo khả } \\
\text { năng phát hiện } \\
\text { rủi ro }\end{array}$} & Không thể phát hiện & Không có cách để phát hiện rủi ro & 10 \\
\hline & Rất khó phát hiện & $\begin{array}{l}\text { Chỉ có thể phát hiện rủi ro khi kiểm tra thật kỹ lưỡng và } \\
\text { không dể thực hiện việc kiểm tra }\end{array}$ & 9 \\
\hline & Khó phát hiện & $\begin{array}{l}\text { Có thể phát hiện rủi ro bằng kiểm tra thủ công, không có quy } \\
\text { trình và phát hiện rủi ro chủ yếu do tình cờ }\end{array}$ & $\begin{array}{l}8 \\
7\end{array}$ \\
\hline & $\begin{array}{l}\text { Khả năng phát hiện } \\
\text { trung bình }\end{array}$ & $\begin{array}{l}\text { Có quy trình kiểm tra nhưng không tự động và chỉ kiểm tra } \\
\text { mấu }\end{array}$ & $\begin{array}{l}6 \\
5\end{array}$ \\
\hline & Có thể phát hiện & Hệ thống được kiểm tra, xem xét nhưng không tự động & $\begin{array}{l}4 \\
3\end{array}$ \\
\hline & Phát hiện được & Hệ thống được kiểm tra và tự động phát hiện & 2 \\
\hline & Chắc chắc phát hiện & Có hệ thống tự động ngăn ngừa rủi ro & 1 \\
\hline
\end{tabular}




\section{CƠ SỞ LÝ THUYẾT}

Có nhiều cách phân loại các rủi ro chuỗi cung ứng, tùy vào cách tiếp cận khác nhau của các tác giả, hoặc theo hướng quản trị các hoạt động của chuỗi cung ứng, hoặc theo hướng tài chính, hoặc có thể dựa vào mức độ phức tạp của hệ thống chuỗi cung ứng. Bảng 3-1 liệt kê các hình thức phân loại rủi ro chuỗi cung ứng của một số nghiên cứu liên quan trên thế giới.

Bảng 3: Phân loại rủi ro chuỗi cung úng

\begin{tabular}{|c|c|c|}
\hline Năm & Loại rủi ro & Nguồn \\
\hline 1993 & $\begin{array}{l}\text { (1) Môi trường, (2) ngành, (3) tổ chức, vấn đề cụ thể, (4) người ra quyết định } \\
\text { liên quan đến các sự thay đổi }\end{array}$ & Ritchie và Marshall (1993) \\
\hline \multirow[t]{2}{*}{2000} & (1) môi trường bên trong, (2) quá trình vận hành, (3) các quyết định & Deloach (2000) \\
\hline & (1) ngoại sinh, (2) nội sinh & Ritchie và Brindley (2000) \\
\hline 2002 & $\begin{array}{l}\text { (1) bên ngoài chuỗi cung ứng, (2) bên trong chuỗi cung ứng (3) mạng lưới liên } \\
\text { quan }\end{array}$ & Juttner và cộng sự (2002) \\
\hline \multirow[t]{3}{*}{2003} & $\begin{array}{l}\text { (1) hoạt động không ổn định, (2) đứt gãy chiến thuật, (3) chiến lược không chắc } \\
\text { chắn. }\end{array}$ & Paulsson và Norrman (2003) \\
\hline & (1) sự phối hợp cung-cầu, (2) sự đứt gãy. & $\begin{array}{l}\text { Kleindorfer và Wassenhove } \\
\text { (2003) }\end{array}$ \\
\hline & (1) môi trường, (2) mạng lưới liên quan, (3) tổ chức & Jüttner và cộng sự (2003) \\
\hline \multirow[t]{4}{*}{2004} & (1) rủi ro hoạt động, (2) thảm họa hoạt động, (3) chiến lược không chắc chắn & Norrman và Lindroth (2004) \\
\hline & (1) quá trình, (2) quản lý, (3) cầu, (4) cung, (5) môi trường & Christopher và Peck (2004) \\
\hline & $\begin{array}{l}\text { (1) Đứt gãy, (2) trì hoãn, (3) hệ thống, (4) dự báo, (5) sở hữu trí tuệ, (6) thu mua, } \\
\text { (7) nợ phải thu, (8) tồn kho, (9) công suất }\end{array}$ & Chopra và Sodhi (2004) \\
\hline & $\begin{array}{l}\text { (1) dòng chảy sản phẩm, (2) dòng chảy thông tin, (3) dòng chảy tiền tệ, (4) an } \\
\text { ninh, (5) hành vi cơ hội, (6) trách nhiệm xã hội }\end{array}$ & Spekman và Davis (2004) \\
\hline \multirow[t]{2}{*}{2005} & (1) kết hợp cung và cầu, (2) đứt gãy trong các hoạt động & Kleindorfer và Saad (2005) \\
\hline & (1) cung, (2) cầu, (3) môi trường & Jüttner (2005) \\
\hline \multirow[t]{3}{*}{2006} & $\begin{array}{l}\text { (1) nội bộ có thể kiểm soát được, (2) nội bộ có thể kiểm soát được một phần, (3) } \\
\text { nội bộ không thể kiểm soát,(4) bên ngoài có thể kiểm soát được, (5) bên ngoài } \\
\text { kiểm soát được một phần, (6) bên ngoài không thể kiểm soát được }\end{array}$ & Wu và cộng sự (2006) \\
\hline & (1) phía cầu, (2) phía cung, (3) thảm họa & Wagner và Bode (2006) \\
\hline & (1) hoạt động, (2) đứt gãy & Tang (2006) \\
\hline \multirow[t]{2}{*}{2007} & (1) chiến lược, (2) chiến thuật, (3) hoạt động & Ritchie và Brindley (2007) \\
\hline & (1) tổ chức, (2) cấp mạng lước, (3) cấp ngành, (4) cấp môi trường & $\begin{array}{l}\text { Gaonkar và Viswanadham } \\
\text { (2007) }\end{array}$ \\
\hline \multirow[t]{3}{*}{2008} & $\begin{array}{l}\text { (1) cung, (2) hoạt động, (3) cầu, (4) an ninh, (5) vĩ mô, (6) chính trị, (7) cạnh } \\
\text { tranh, (8) nguồn lực }\end{array}$ & Manuj và Mentzer (2008) \\
\hline & $\begin{array}{l}\text { (1) phía cầu, (2) phía cung, (3) quy định, (4) luật pháp và quan liên, (5) cơ sở hạ } \\
\text { tầng; (6) thảm họa }\end{array}$ & Wagner và Bode (2008) \\
\hline & (1) cung, (2) quy trình, (3) cầu, (4) sở hữu trí tuệ, (5) hành vi, (6) chính trị/xã hội & Tang và Tomlin (2008) \\
\hline 2009 & $\begin{array}{l}\text { (1) cung, (2) quy trình, (3) cầu, (4) đứt gãy hiếm xãy ra nhưng nghiêm trọng, (5) } \\
\text { khác, (6) hành vi, (7) chính trị và xã hội }\end{array}$ & Tang và Tomlin (2009) \\
\hline 2011 & $\begin{array}{l}\text { (1) cầu, (2) chậm trễ, (3) gián đoạn, (4) tồn kho, (5) ngừng sản xuất, (6) công } \\
\text { suất nhà máy, (7) cung, (8) hệ thống, (9) nhà nước, (10) phân phối }\end{array}$ & $\begin{array}{l}\text { Tummala và Schoenherr } \\
\text { (2011) }\end{array}$ \\
\hline 2013 & $\begin{array}{l}\text { (1) phía cung, (2) phía nhà sản xuất, (3) phía cầu, (4) phía vận tải, (5) thông tin, } \\
\text { (6) môi trường }\end{array}$ & $\begin{array}{l}\text { Punniyamoorthy và cộng sự } \\
\text { (2013) }\end{array}$ \\
\hline
\end{tabular}

(Nguồn: Liu và Ding. 2014) [5] 


\section{KẾT QUẢ NGHIÊN CỨU}

Bảng 4: Kết quả phân tích rủi ro

\begin{tabular}{|c|c|c|c|c|c|c|c|}
\hline & $\begin{array}{c}\text { Mã } \\
\text { rủi } \\
\text { ro }\end{array}$ & Rủi ro tiềm ẩn & $\begin{array}{c}\text { Mức độ nghiêm } \\
\text { trọng }(\mathrm{S})\end{array}$ & $\begin{array}{c}\text { Tần số xuất } \\
\text { hiện }(\mathrm{O})\end{array}$ & $\begin{array}{c}\text { Khả năng } \\
\text { phát hiện (D) }\end{array}$ & $\begin{array}{l}\mathrm{RSV} \\
(\mathrm{SxO})\end{array}$ & $\begin{array}{c}\mathrm{RPN} \\
(\mathrm{SxOxD})\end{array}$ \\
\hline \multirow{5}{*}{$\begin{array}{l}\text { Rủi ro } \\
\text { từ } \\
\text { nguồn } \\
\text { cung }\end{array}$} & $\mathrm{S} 1$ & $\begin{array}{l}\text { Nhà cung cấp bị phá } \\
\text { sản }\end{array}$ & 8,67 & 1,00 & 3,33 & 8,67 & 28,89 \\
\hline & $\mathrm{S} 2$ & $\begin{array}{l}\text { Phụ thuộc vào một nhà } \\
\text { cung cấp }\end{array}$ & 8,33 & 3,67 & 4,67 & 30,56 & 142,59 \\
\hline & S3 & $\begin{array}{l}\text { Chất lượng đầu vào } \\
\text { không ồn định }\end{array}$ & 6,67 & 3,33 & 1,33 & 22,22 & 29,63 \\
\hline & $\mathrm{S} 4$ & $\begin{array}{l}\text { Các rủi ro từ nhà cung } \\
\text { cấp của nhà cung cấp }\end{array}$ & 3,33 & 2,33 & 5,33 & 7,78 & 41,48 \\
\hline & S5 & $\begin{array}{l}\text { Nhà cung cấp giao } \\
\text { hàng bị chậm trễ }\end{array}$ & 4,33 & 5,33 & 5,67 & 23,11 & 130,96 \\
\hline \multirow{5}{*}{$\begin{array}{l}\text { Rủi ro } \\
\text { từ } \\
\text { nguồn } \\
\text { cầu }\end{array}$} & D1 & $\begin{array}{l}\text { Dự báo cao hơn nhu } \\
\text { cầu thực tế }\end{array}$ & 2,33 & 333 & 8,33 & 7,78 & 64,81 \\
\hline & D2 & $\begin{array}{l}\text { Dự báo thấp hơn nhu } \\
\text { cầu thực tế }\end{array}$ & 2,00 & 3,33 & 8,33 & 6,67 & 55,56 \\
\hline & D3 & Mất khách hàng lớn & 2,00 & 1,00 & 7,33 & 2,00 & 14,67 \\
\hline & D4 & $\begin{array}{l}\text { Đối thủ cạnh trạnh gay } \\
\text { gắt }\end{array}$ & 3,33 & 2,33 & 8,33 & 7,78 & 64,81 \\
\hline & D5 & Khách hàng bị phá sản & 2,00 & 1,33 & 6,33 & 2,67 & 16,89 \\
\hline \multirow{5}{*}{$\begin{array}{c}\text { Rủi ro } \\
\text { trong } \\
\text { sản } \\
\text { xuất }\end{array}$} & $\mathrm{P} 1$ & $\begin{array}{l}\text { Chất lượng không ổn } \\
\text { định }\end{array}$ & 4,33 & 4,67 & 7,00 & 20,22 & 141,56 \\
\hline & $\mathrm{P} 2$ & $\begin{array}{l}\text { Thiết bị không đáp ứng } \\
\text { nhu cầu sản xuất }\end{array}$ & 5,67 & 3,33 & 5,33 & 18,89 & 100,74 \\
\hline & $\mathrm{P} 3$ & Năng suất sản xuất thấp & 2,33 & 4,67 & 3,33 & 10,89 & 36,30 \\
\hline & P4 & $\begin{array}{l}\text { Thời gian tạo sản phẩm } \\
\text { mới chậm }\end{array}$ & 5,67 & 4,67 & 4,33 & 26,44 & 114,59 \\
\hline & P1 & $\begin{array}{l}\text { Chất lượng không ổn } \\
\text { định }\end{array}$ & 4,33 & 4,67 & 7,00 & 20,22 & 141,56 \\
\hline \multirow{2}{*}{$\begin{array}{l}\text { Rủi ro } \\
\text { trong } \\
\text { quản } \\
\text { lý }\end{array}$} & $\mathrm{C} 1$ & $\begin{array}{l}\text { Gặp khó khăn về tài } \\
\text { chính }\end{array}$ & 5,67 & 1,00 & 2,67 & 5,67 & 15,11 \\
\hline & $\mathrm{C} 2$ & $\begin{array}{l}\text { Liên lạc giữa các } \\
\text { phòng ban không tốt }\end{array}$ & 4,33 & 4,33 & 2,00 & 18,78 & 37,56 \\
\hline
\end{tabular}




\begin{tabular}{|c|c|c|c|c|c|c|c|}
\hline & C3 & $\begin{array}{l}\text { Kết hợp dự báo và kế } \\
\text { hoạch không chặt chẽ }\end{array}$ & 5,33 & 2,67 & 2,33 & 14,22 & 33,19 \\
\hline & $\mathrm{C} 4$ & $\begin{array}{l}\text { Quan hệ với đối tác } \\
\text { không tốt }\end{array}$ & 2,33 & 2,00 & 3,67 & 4,67 & 17,11 \\
\hline & C5 & $\begin{array}{l}\text { Hệ thống thông tin hỗ } \\
\text { trợ kém }\end{array}$ & 2,67 & 2,67 & 4,67 & 7,11 & 33,19 \\
\hline & B1 & $\begin{array}{l}\text { Hạ tầng giao thông } \\
\text { Việt Nam không đảm } \\
\text { bảo }\end{array}$ & 3,67 & 4,33 & 7,67 & 15,89 & 121,81 \\
\hline & B2 & $\begin{array}{l}\text { Kho bãi không đủ sức } \\
\text { chứa }\end{array}$ & 4,33 & 4,33 & 3,00 & 18,78 & 56,33 \\
\hline $\begin{array}{l}\text { trong } \\
\text { phân }\end{array}$ & B3 & $\begin{array}{l}\text { Hàng hóa vận chuyển } \\
\text { bị trộm cướp }\end{array}$ & 5,67 & 2,33 & 2,00 & 13,22 & 26,44 \\
\hline & B4 & $\begin{array}{l}\text { Không đủ phương tiện } \\
\text { tải phục vụ giao hàng }\end{array}$ & 4,67 & 5,33 & 4,00 & 24,89 & 99,56 \\
\hline & B5 & $\begin{array}{l}\text { Tuyến đường vận } \\
\text { chuyển dài và khó } \\
\text { khăn }\end{array}$ & 5,33 & 3,33 & 1,67 & 17,78 & 29,63 \\
\hline & E1 & Thảm họa thiên nhiên & 7,67 & 1,00 & 9,67 & 7,7 & 74,1 \\
\hline $\begin{array}{l}\text { Ku1 ro } \\
\text { từ môi }\end{array}$ & $\mathrm{E} 2$ & Chiến tranh, khủng bố & 8,00 & 1,00 & 9,67 & 8,0 & 77,3 \\
\hline trường & E3 & Đình công & 5,67 & 1,33 & 9,33 & 7,6 & 70,5 \\
\hline $\begin{array}{l}\text { bên } \\
\text { nooài }\end{array}$ & E4 & Thay đổi về luật & 2,00 & 1,00 & 8,67 & 2,0 & 17,3 \\
\hline & E5 & Thay đổi về thuế & 2,00 & 1,00 & 6,67 & 2,0 & 13,3 \\
\hline
\end{tabular}

(Nguồn: Tính toán từ dữ liệu thu thập sau phỏng vấn)

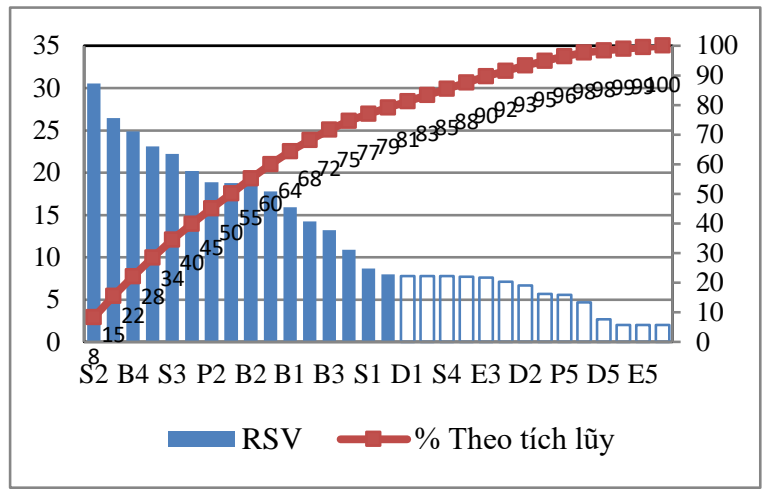

Hình 1: Pareto hệ số mức độ rủi ro RSV xác định

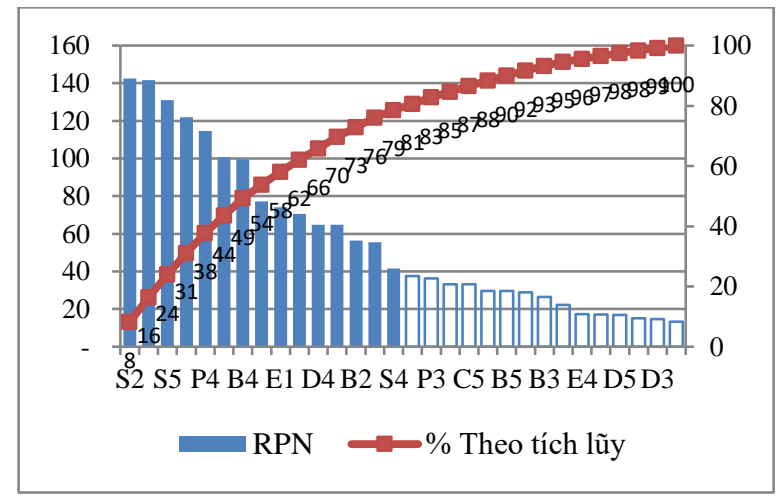

Hình 2: Pareto hệ số ưu tiên rủi ro xác định

Kết quả phân tích hệ số rủi ro RSV theo biểu đồ Pareto (Hình 1) cho thấy $80 \%$ rủi ro xảy ra và ảnh hưởng đến chuỗi cung ứng tập trung vào 16 rủi ro (từ 30 rủi ro được nhận diện ban đầu), được liệt kê trong Bảng 5. Tương tự như hệ số RSV, biểu đồ Pareto (Hình 2) hệ số ưu tiên rủi ro RPN xác định được 15 rủi ro chiếm $80 \%$ ảnh hưởng nhiều nhất đến chuỗi cung ứng, được liệt kê trong Bảng 6. 
ĐÁNH GIÁ RỦI RO TRONG HOẠT ĐỘNG CHUỖI CUNG ÚNG:

TRUỜNG HỢP CÔNG TY TNHH SYNTHOMER VIẸT NAM

Bảng 5: Các rủi ro có hệ số RSV cần ưu tiên giải quyêt

\begin{tabular}{|l|l|r|}
\hline Mã rủi ro & \multicolumn{1}{|c|}{ Rủi ro tiềm ẩn } & Hệ số RSV \\
\hline S2 & Phụ thuộc vào một nhà cung cấp & 30,56 \\
\hline P4 & Thời gian tạo sản phẩm mới chậm & 26,44 \\
\hline B4 & Không đủ phương tiện vận chuyển phục vụ & 24,89 \\
\hline S5 & Nhà cung cấp giao hàng bị chậm trễ & 23,11 \\
\hline S3 & Chất lượng đầu vào không ổn định & 22,22 \\
\hline P1 & Chất lượng không ổn định & 20,22 \\
\hline P2 & Thiết bị không đáp ứng được nhu cầu sản xuất & 18,89 \\
\hline C2 & Liên lạc giữa các phòng ban không tốt & 18,78 \\
\hline B2 & Kho bãi không đủ sức chứa & 18,78 \\
\hline B5 & Tuyến đường vận chuyền dài và khó khăn & 17,78 \\
\hline B1 & Hạ tầng giao thông không đảm bảo & 15,89 \\
\hline C3 & Kết hợp dự báo và kế hoạch không chặt chẽ & 14,22 \\
\hline B3 & Hàng hóa vận chuyển bị trộm cướp & 13,22 \\
\hline P3 & Năng suất sản xuất thấp & 10,89 \\
\hline S1 & Nhà cung cấp bị phá sản & 8,67 \\
\hline E2 & Chiến tranh và khủng bố & 8,00 \\
\hline
\end{tabular}

(Nguồn: Tính toán tì dĩ liệu thu thập sau phỏng vấn)

Bảng 6: Các rủi ro có hệ số RPN cần ưu tiên

\begin{tabular}{|l|l|r|}
\hline Mã rủi ro & \multicolumn{1}{|c|}{ Rủi ro tiềm ẩn } & Hệ số PRN \\
\hline S2 & Phụ thuộc vào một nhà cung cấp & 142,59 \\
\hline P1 & Chất lượng không ổn định & 141,56 \\
\hline S5 & Nhà cung cấp giao hàng bị chậm trễ & 142,59 \\
\hline P4 & Thời gian tạo sản phẩm mới chậm & 141,56 \\
\hline B4 & Không đủ phương tiện vận chuyển phục vụ & 130,96 \\
\hline B1 & Hạ tầng giao thông không đảm bảo & 121,81 \\
\hline P2 & Thiết bị không đáp ứng được nhu cầu sản xuất & 114,59 \\
\hline E2 & Chiến tranh và khủng bố & 100,74 \\
\hline E1 & Thảm họa thiên nhiên & 99,56 \\
\hline E3 & Đình công & 77,30 \\
\hline D4 & Đối thủ cạnh trạnh gay gắt & 74,10 \\
\hline B2 & Kho bãi không đủ sức chứa & 70,50 \\
\hline D2 & Dự báo thấp hơn nhu cầu thực tế & 64,81 \\
\hline D1 & Dự báo cao hơn nhu cầu thực tế & 64,81 \\
\hline S4 & Các rủi ro từ nhà cung cấp của nhà cung cấp & 56,33 \\
\hline & & \\
\hline
\end{tabular}

(Nguồn: Tính toán tì dũ liệu thu thập sau phỏng vấn) 


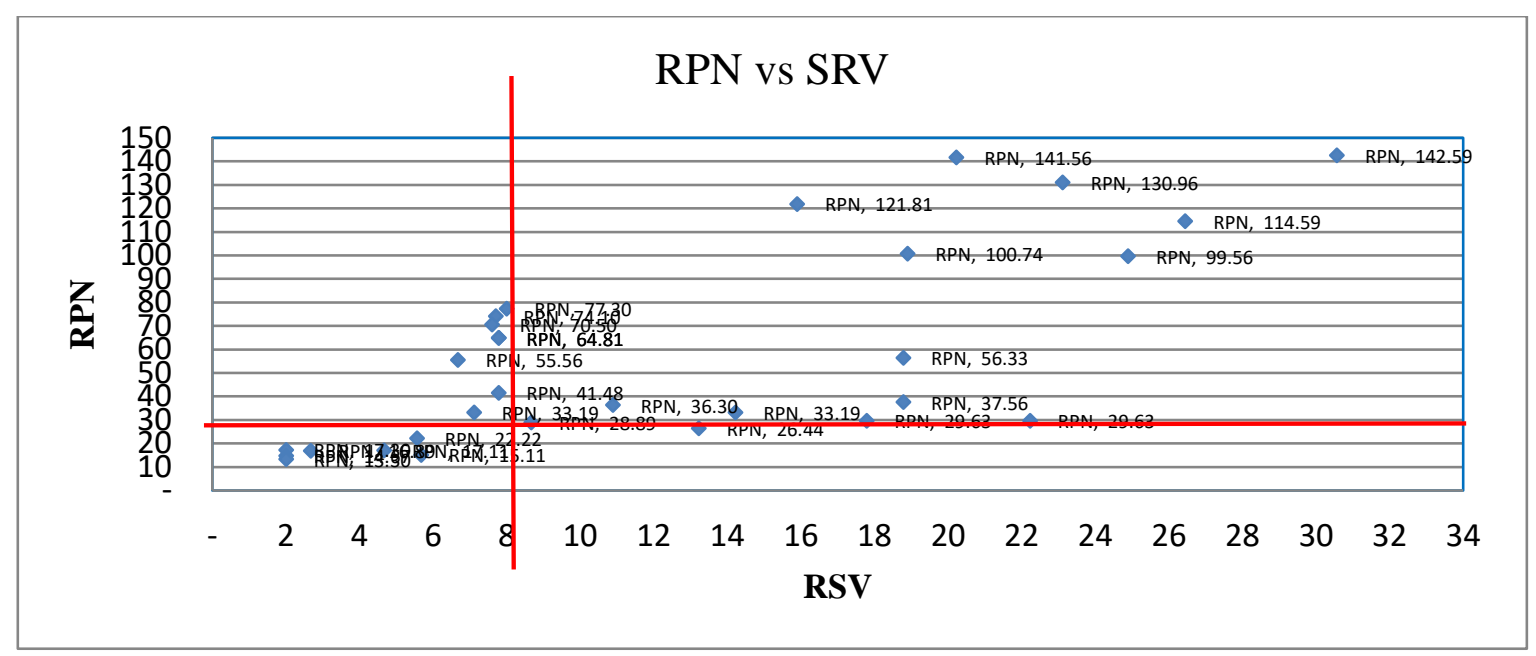

Hình 3: Biểu đồ Scatter xác định rủi ro ưu tiên xủ lý

Với 16 rủi ro có hệ số rủi ro RSV và 15 rủi ró hệ số ưu tiên RPN cao, việc tiếp theo là tìm ra những rủi ro nào trong các rủi ro này có cả hai hệ số RSV và RPN đều cao và đó cũng chính là những rủi ro cần được xem xét và ưu tiên xử lý trước. Biểu đồ Scatter sẽ giúp tìm ra mối quan hệ giữa hai hệ số RSV và RPN (Hình 3). Dựa vào kết quả riêng biệt cho từng hệ số, mức giới hạn ưu tiên rủi ro cho RSV là từ 8,0 trở lên, mức giới hạn ưu tiên rủi ro cho RPN là từ 37,6 trở lên. Biểu đồ Scatter cho thấy có tổng cộng 8 rủi ro vừa có hệ số RSV cao và vừa có hệ số $\mathrm{RPN}$ cao, trong đó, 2 rủi ro do từ nguồn cung, 3 rủi ro từ khâu sản xuất tại Synthomer Việt Nam, và 3 rủi ro trong phân phối. Nguồn cầu và môi trường bên ngoài không có rủi ro nào nằm trong nhóm rủi ro cần ưu tiên xử lý.

Bảng 7: Danh sách rủi ro cần ưu tiên xủ lý

\begin{tabular}{|c|c|l|r|r|}
\hline $\begin{array}{c}\text { Số thứ } \\
\text { tự }\end{array}$ & Mã rủi ro & \multicolumn{1}{|c|}{ Rủi ro tiềm ẩn } & Hệ số RSV & Hệ số RPN \\
\hline 1 & S2 & Phụ thuộc vào một nhà cung cấp & 30,56 & 142,59 \\
\hline 2 & S5 & Nhà cung cấp giao hàng bị chậm trễ & 23,11 & 130,96 \\
\hline 3 & P4 & Thời gian tạo sản mới chậm & 26,44 & 114,59 \\
\hline 4 & P1 & Sản xuất hàng hoá chất lượng không ổn định & 20,22 & 141,56 \\
\hline 5 & P2 & Thiết bị không đáp ứng được nhu cầu sản xuất & 18,89 & 100,74 \\
\hline 6 & B4 & Không đủ phương tiện vận chuyển phục vụ & 24,89 & 99,56 \\
\hline 7 & B1 & Hạ tầng giao thông tại Việt Nam không đảm bảo & 15,89 & 121,81 \\
\hline 8 & B2 & Kho bãi không đủ sức chứa & 18,78 & 56,33 \\
\hline
\end{tabular}

(Nguồn: Tính toán từ dữ liệu thu thập sau phỏng vấn)

Rủi ro do phu thuộc vào một nhà cung cấp Trong các rủi ro trên, rủi ro phụ thuộc vào nhà cung cấp có hai chỉ số RSV và RPN cao nhất với RSV 30,56 và RPN là 142,59. Giải thích cho kết quả này, các chuyên gia nhận định rằng việc phụ thuộc vào nhà cung cấp là rủi ro chủ yếu dẫn đến thiếu hụt nguyên vật liệu sản xuất gây định trệ hoạt động sản xuất, không đủ hàng hóa cung cấp cho khách hàng. Theo các chuyên gia, rủi ro này gây ảnh hưởng khá nghiêm trọng đến mức độ hài lòng của khách hàng. Về tấn số xuất hiện, các chuyên gia đều trả lời rằng rủi ro này đã và đang xảy ra tại Synthomer Việt Nam và có khả năng xảy ra trong tương lai nếu Synthomer vẫn duy trì hoạt động như hiện nay. Mức độ ảnh hưởng khá nghiêm trọng và có khả năng xảy ra nhưng Synthomer Việt Nam lại không có biện pháp nào hữu hiệu để có thể phát hiện ra rủi ro này vì rủi ro này nằm ngoài tầm kiểm soát nội bộ của Synthomer Việt Nam và chỉ có thể phát hiện rủi ro khi được thông báo bởi chính nhà cung cấp. 
Rủi ro do nhà cung cấp giao hàng bị chậm trễ Ngoài việc phụ thuộc quá nhiều vào một nhà cung cấp thì một rủi ro khác do nhà cung cấp gây ảnh hưởng đến hoạt động của chuỗi cung ứng Synthomer Việt Nam đó là rủi ro do nhà cung cấp giao hàng bị chậm trễ. Cũng giống như phụ thuộc vào một nhà cung cấp, nhà cung cấp giao hàng bị chậm trễ cũng dẫn đến nguy cơ thiếu hụt nguyên vật liệu cho sản xuất gây ảnh hưởng đến tiến đột giao hàng cho khách hàng. Ghi nhận của các chuyên gia thì các công ty thương mại tại Việt Nam là đối tượng tạo ra rủi ro này nhiều nhất, nguyên nhân là do các công ty thương mại phải nhập hàng từ nước ngoài và khả năng quản lý hàng tồn kho cũng như yếu kém trong khâu lập kế hoạch nhập hàng. Rủi ro gây hậu quả nghiêm trọng, rủi ro cũng đã từng xảy ra nhiều trong quá khứ nhưng hiện nay Synthomer Việt Nam vẫ் chưa có biện pháp phòng tránh nào hữu hiệu ngoài việc tăng lượng tồn kho nguyên vật liệu để dự phòng rủi ro.

Rủi ro do thời gian tạo sản phẩm mới chậm Synthomer Việt Nam không có bộ phận Nghiên cứu và Phát triển $(\mathrm{R} \& \mathrm{D})$, mọi công tác nghiên cứu và phát triển sản phẩm mới đều phải phụ thuộc vào sự hỗ trợ của tập đoàn. Trong vòng 5 năm trở lại đây, Synthomer không có sản phẩm mới để đáp ứng nhu cầu ngày càng cao, đặc biệt là Synthomer Việt Nam vẫn chưa có dòng sản phẩm xanh không gây hại môi trường là dòng sản phẩm mà khách hàng đang hướng đến.

Rủi ro do sản xuất hàng hóa không ổn định Chất lượng hàng hoá sản xuất ra không ổn định cũng là rủi ro cao đối với Synthomer Việt Nam. Theo báo cáo của Ban lãnh đạo Công ty thì trong năm 2015 có 5 sự cố chất lượng và trong năm 2016, tính đến hết tháng 11 đã ghi nhận 7 sự cố sản xuất. Chất lượng hàng hóa cũng là lý do khách hàng khiếu nại nhiều nhất. Trong năm 2014, 15 trong tổng số 17 khiếu nại của khách hàng liên quan đến chất lượng; con số này trong năm 2015 là 10 trên 12; còn riêng trong tháng 11 năm 2016 thì 10 trong tổng số 11 khiếu nại của khách hàng liên quan đến chất lượng hàng hóa.

Rủi ro do thiết bị không đáp úng nhu cầu sản xuất Rủi ro do thiết bị máy móc không đáp ứng đủ nhu cầu sản xuất cũng được các chuyên gia đánh giá là một trong những rủi ro gây ảnh hưởng đến hoạt động của chuỗi cung ứng. Tổng công suất khai thác trong năm 2015 chỉ chiếm $70 \%$ công suất tối đa nhưng rủi ro do máy móc không đáp ứng nhu cầu sản xuất lại bị đánh giá là rủi ro cao. Sản lượng bán ra của Synthomer Việt Nam không đồng đều trong các tháng trong năm mà có tính chất mùa vụ, 6 tháng đầu năm luôn có sản lượng bán ra ít hơn so với 6 tháng cuối năm. Do thời hạn sử dụng của sản phẩm ngắn cộng với quy định không trữ hàng tồn kho để đảm bảo chất lượng sản phẩm nên Synthomer Việt Nam không thể sản xuất để trữ hàng và bán vào mua cao điểm. Do đó, các tháng cuối năm đặc biệt là quý IV hàng năm Công ty luôn trong tình trạng không đủ công suất để đáp ứng nhu cầu khách hàng.

Rủi ro do không đủ phương tiện vận tải phuc vu giao hàng Công ty hiện đang ký hợp đồng với 3 nhà vận tải để cung cấp dịch vụ chuyên chở nguyên liệu nhập khẩu và vận tải hàng hoá phân phối cho khách hàng nhưng khi trao đổi với các chuyên gia đang phụ trách lĩnh vực logistics cho Synthomer Việt Nam thì nhu cầu vận chuyển hàng hoá vẫn không đáp ứng được nhu cầu và thường gây ra những phản hồi không tốt của khách hàng về tình trạng giao hàng của Synthomer Việt Nam. Giải thích cho nguyên nhân này, các chuyên gia cho rằng do đặc tính kinh doanh mùa vụ của Synthomer Việt Nam nên các công ty vận tải gặp khó khăn trong vấn đề cung cấp dịch vụ cho Synthomer Việt Nam vào mùa cao điểm, họ cho rằng việc đầu tư số lượng xe tải cung cấp đủ yêu cầu của Synthomer Việt Nam vào mùa cao điểm thì họ gặp khó khăn trong mùa thấp điểm khi nhu cầu về vận tải của Synthomer giảm xuống, điều này ảnh hưởng đến doanh thu của các công ty vận tải, do đó họ vẫn đang cố xoay sở trong một số lượng xe nhất định.

Rủi ro do hạ tầng giao thông tại Việt Nam không đảm bảo Hệ thống giao thông Việt Nam với mật độ tham gia giao thông cao, tốc độ của các phương tiện di chuyển khá chậm và nguy cơ xảy ra tai nạn giao thông cũng rất lớn là các vấn đề gây ảnh hưởng đến chuỗi cung ứng của Synthomer Việt Nam trong khâu phân phối hàng hoá. Với hơn $90 \%$ sản lượng hàng hoá tiêu thụ tại thị trường Việt Nam, Synthomer Việt Nam phải điều phối hàng hoá cung cấp cho các tỉnh thành từ Bắc đến Nam và đang gặp phải các rủi ro trong khâu phân phối như công tai nạn giao thông, kẹt xe gây ảnh hưởng sự hài lòng của khách hàng.

Rủi ro do kho bãi không đủ sức chứa Các chuyên gia phụ trách quản lý kho của Synthomer Việt Nam cho rằng diện tích, hệ thống kho bãi hiện nay của Synthomer Việt Nam không đủ để đáp ứng nhu cầu. Cụ thể, Công ty chỉ có 2 bồn chứa hàng thành phẩm với dung tích mỗi bồn chứa là 50 tấn, trong khi đó Synthomer đang sản xuất 8 mặt hàng cần sử dụng bồn chứa do đó bộ phận sản xuất phải gặp khó khăn trong việc lặp kế hoạch sản xuất và luân phiên sử dụng 2 bồn chứa này. Chính vì khó khăn này, Công ty thường gặp một số vấn đề như hàng hoá kém chất lượng do các sản phẩm bị lẫn vào nhau do vệ sinh bồn chứa 
trước khi sử dụng không làm sạch hết các chất trước đó, kế hoạch sản xuất bị đình trệ do không đủ bồn chứa hàng thành phẩm. Bên cạnh việc thiếu hụt bồn chứa hàng thành phẩm, diện tích kho chứa sản phẩm khác cũng được ghi nhận không đủ đáp ứng lượng hàng tồn kho, hàng hoá thường phải để bên ngoài dưới ánh nắng mặt trời hoặc chịu tác động của nước mưa gây ảnh hưởng lớn đến chất lượng sản phẩm và bao bì.

\section{HÀM Ý QUẢN TRI}

Từ kết quả phân tích trên, với 8 rủi ro trong chuỗi cung ứng của Synthomer Việt Nam được xác định cần được ưu tiên xử lý, nghiên cứu đề xuất các hàm ý quản trị tương ứng nhằm cải thiện hiệu quả chuỗi cung ứng của Công ty như sau:

Đối với rủi ro Phu thuộc vào một nhà cung cấp, do phần lớn nguyên vật liệu phục vụ sản xuất tại Synthomer Việt Nam phải nhập khẩu từ nước ngoài nên việc xử lý rủi ro phụ thuộc vào nhà cung cấp là một nhiệm vụ cần thiết và không dễ thực hiện. Công ty nên: 1) Đối với các nguyên liệu do khách hàng chỉ định nhà sản xuất, Công ty cần có hợp đồng cung ứng, ràng buột trách nhiệm rõ ràng đối với nhà cung cấp, tiến hành đánh giá khả năng của nhà cung cấp hàng năm nhằm đảm bảo khả năng cung ứng của nhà cung cấp, đồng thời, Công ty cần xây dựng mối quan hệ chặt chẽ với nhà cung cấp cũng như thường xuyên cập nhật thông tin, dự báo để nhà cung cấp nắm rõ nhu cầu của Công ty; với các nhà sản xuất ở nước ngoài, do thời gian vận chuyển lâu và có nhiều nguy cơ trễ hàng vì thời gian vận chuyển trên biển kéo dài, Công ty cần cân nhắc và xây dựng mức tồn kho cho các nguyên vật liệu này cao hơn các nhóm mặt hàng khác; 2 ) Đối với các nguyên liệu mua qua nhà phân phối trong nước: Bên cạnh việc xây dựng mối quan hệ với nhà cung cấp hiện tại, Công ty cần xây dựng chính sách ít nhất hai nhà phân phối cho mỗi nguyên vật liệu. Việc duy trì hai nhà cung cấp sẽ đảm bảo nguồn nguyên vật liệu ổn định, nếu một trong các nhà phân phối không thể cung cấp nguyên liệu thì sẽ có nhà phân phối khác hỗ trợ. Tuy nhiên, Công ty cũng cần cân nhắc đến vấn đề về giá nguyên liệu nếu số lượng nguyên vật liệu chia cho nhiề nhà phân phối thì lợi thế về giá nếu mua số lượng lớn sẽ bị ảnh hưởng; Công ty cũng nên duy trì nhiều nhà phân phối cho cùng một nhà sản xuất thì rủi ro vẫn có nguy cơ xảy ra nếu nhà sản xuất gặp sự cố. Do đó, nếu nguyên liệu không bị ràng buộc về nhà sản xuất, Công ty cần kết hợp với bộ phận $R \& D$ của Tập đoàn tìm kiếm nhà sản xuất khác với nhà sản xuất hiện tại giúp giảm thiếu nguy cơ sự cố xảy ra tại nhà sản xuất.

Đối với rủi ro Nhà cung cấp giao hàng bị chậm trễ, vấn đề giảm thiểu việc nhà cung cấp giao hàng bị chậm trễ phụ thuộc nhiều vào sự giám sát, theo dõi nhà cung cấp của bộ phận thu mua nguyên vật liệu. Do đó, Công ty cần có một quy trình theo dõi đơn đặt hàng và một hệ thống tự động theo dõi đơn hàng, đảm bảo nguyên vật liệu được giao hàng đúng theo kế hoạch. Ngoài ra, với các lý do khách quan từ phía nhà cung cấp, để đảm bảo tiến độ sản xuất không bị ảnh hưởng, Công ty cần có một chính sách về mức tồn kho phù hợp cho từng nguyên vật liệu dựa vào đặc điểm của từng loại nguyên vật liệu, từng nhà cung cấp thì có mức tồn kho khác nhau.

Đối với rủi ro Thời gian thay đổi sản phẩm chậm, do thời gian thay đổi sản phẩm phụ thuộc nhiều vào quyết định và chiến lược của Tập đoàn Synthomer nên Synthomer Việt Nam cần có những đề xuất và kế hoạch rõ ràng báo cáo cho các cấp quản lý hiểu rõ những nguy cơ trong kinh doanh tại Công ty gây nên bởi thời gian thay đổi sản phẩm chậm này gây ra. Để làm được việc này, bộ phận kinh doanh cũng như cấp lãnh đạo của Tập đoàn Synthomer cần phải kết hợp với nhau và đưa ra những kịch bản chi tiết cũng như những như cầu cụ thể về sản phẩm mà Công ty cần để đáp ứng cho khách hàng của Synthomer Việt Nam.

Đối với rủi ro Sản xuất hàng hoá có chất luợng không ổn định, để giảm thiểu rủi ro hàng hóa có chất lượng không ổn định do quá trình sản xuất gây ra, Công ty cần tập trung cải tiến quy trình sản xuất bằng cách giải quyết triệt để nguyên nhân gây ra hàng hóa bị hư hỏng trong quá trình sản xuất. Để thực hiện được việc này, cần phải có sự chỉ đạo và một quy trình chuẩn áp dụng cho bộ phận sản xuất trong việc điều tra nguyên nhân và rút ra kết luận và giải pháp cụ thể để loại trừ sự cố lặp đi lặp lại. Bên cạnh đó, Công ty cần tổ chức các khóa đào tạo và huấn luyện về quản lý chất lượng và kỹ thuật vận hành đúng theo quy trình nhằm nâng cao kỹ năng của đội ngũ sản xuất.

Đối với rủi ro Thiết bi không đáp ứng nhu cầu sản xuất, Synthomer Việt Nam xây dựng chiến lược kinh doanh: 1) Hoặc là chiến lược gia tăng lợi nhuận dựa trên phát triển thị trường và doanh số với việc đầu tư thêm thiết bị máy móc và dự trù ngân sách cho kế hoạch này (Quyết định này cần phải có sự hỗ trợ và phê duyệt của các cấp lãnh đạo cấp cao của tập đoàn Synthomer và Tổng giám đốc nhà máy Synthomer Việt Nam sẽ là người chịu trách nhiệm triển khai kế hoạch này), hoặc là 2) Chiến lược gia tăng lợi nhuận 
dựa trên sản phẩm có lợi nhuận cao, theo đó, Công ty sẽ vẫn duy trì sản lượng hiện tại nhưng sẽ tập trung vào các sản phẩm có lợi nhuận cao. Việc này sẽ được thực hiện bởi bộ phận quản lý kinh doanh. Bộ phận kinh doanh sẽ xem xét và quyết định không tiếp tục bán các sản phẩm có doanh số và sản lượng thấp, các sản phẩm có nguy cơ bị đào thải trong tương lai. Việc ngưng bán các sản phẩm này sẽ làm giảm gánh nặng về công suất máy móc không đủ đáp ưng nhu cầu sản xuất trong mùa cao điểm.

Đối với rủi ro Không đủ phuơng tiện vận tải phuc vu giao hàng, Công ty cần xem xét đến kế hoạch tìm kiếm một nhà cung cấp khác thay thế hoặc tìm kiếm thêm một nhà cung cấp thứ hai. Tuy nhiên, Công ty cũng nên cân nhắc đến vấn đề chi phi vận tải khi tiến hành các kế hoạch này. Ngoài việc tìm kiếm các nhà cung cấp dịch vụ vận tải khải khác, Công ty cũng có thể xem xét kế hoạch mua mới hoặc thuê phương tiện vận tải trong dài hạn và tự điều phối giao hàng, như vậy Công ty sẽ chủ động hơn trong hoạt động giao hàng.

Đối với rủi ro Ha tầng giao thông không đảm bảo, do cơ sở hạ tầng giao thông không đảm bảo nằm ngoài khả năng xử lý của Công ty nên Synthomer Việt Nam chỉ có thể chọn phương án chuyển giao rủi ro này sang cho các bên thứ ba bằng cách chuyển trách nhiệm này sang cho nhà cung cấp dịch vụ vận tải bằng cách yêu cầu các nhà cung cấp dịch vụ vận tải phải đảm bảo tiến độ giao hàng đúng theo yêu cầu, các biện pháp chế tài thể hiện rõ trong các hợp đồng giữa Công ty và nhà cung cấp dịch vụ vận tải hàng hóa cho công ty. Phương án chuyển giao rủi ro này cũng có thể được thực hiện bằng cách Công ty ký hợp đồng bảo hiểm hàng hóa cho nguyên vật liệu và thành phẩm thuộc trách nhiệm quản lý trên đường đến Công ty và trên đường đi đến nơi giao hàng cho khách hàng.

Đối với rủi ro Kho bãi không đủ sức chứa, Công ty nên xử lý theo hai phương án: 1) Giảm lượng hàng tồn kho; và 2) Đầu tư thêm kho bãi bằng cách xây dựng thêm bồn chứa hàng, mở rộng diện tích kho hoặc có thể thuê kho bên ngoài. Với phương án đầu tiên là giảm lượng hàng tồn kho thì Công ty phải hết sức cân nhắc về các rủi ro khác có thể xảy nếu lượng hàng tồn kho quá thấp. Với phương án thứ hai thì cần phải có sự phê duyệt từ Ban lãnh đạo Tập đoàn trong việc phân bổ ngân sách và nguồn vốn.

\section{KẾT LUẬN}

Nghiên cứu này đã xác định và đánh giá mức độ các rủi ro trong hoạt động của chuỗi cung ứng Synthomer Việt Nam, từ đó đề xuất một số hàm ý quản trị tương ứng với từng rủi ro cần ưu tiên xử lý. Có nhiều hàm ý quản trị khác nhau để xử lý một rủi ro nào đó; việc chọn hàm ý quản trị như thế nào phụ thuộc nhiều vào mục tiêu của Công ty và vào tầm nhìn của ban lãnh đạo Công ty. Kết quả nghiên cứu này gắn liền với thực trạng hoạt động của chuỗi cung ứng Công ty Synthomer Việt Nam trong thời điểm nghiên cứu, do đó các hàm ý quản trị đề xuất phù hợp với thực trạng của Công ty hiện nay. Khi bối cảnh kinh doanh và hoạt động chuỗi cung ứng thay đổi, Công ty nên tiến hành đánh giá lại các rủi ro. Kết quả nghiên cứu là cơ sở giúp Synthomer Việt Nam xem xét và xử lý các rủi ro hiện tại theo mức độ ưu tiên đã xác định. Do hạn chế về khoảng cách vị trí địa lý và thời gian làm việc của các chuyên gia tham gia phỏng vấn nên các nội dung nghiên cứu chuyên sâu hơn nữa của đề tài chưa thể thực hiện được. Tuy vậy, các nghiên cứu hướng đến việc giúp cải thiện hoạt động quản trị chuỗi cung ứng tại Synthomer Việt Nam sao cho ngày càng hiệu quả hơn vẫn luôn là rất cần thiết đối với Công ty nói riêng và với Tập đoàn nói Synthomer chung.

\section{TÀI LIỆU THAM KHẢO}

[1] Tummala, R., và Schoenherr, T. (2011). Assessing and managing risks using the supply chain risk management process (SCRMP). Supply Chain Management: An International Journal, 16(6), 474-483 [Online]. Available: https://www.researchgate.net/publication/235251515

[2] Minh Hương (2016). Doanh nghiệp Việt và chuỗi giá trị toàn cầu. Viện chiến lược và chính sách tài chính [Online]. Available:http://www.mof.gov.vn/webcenter/portal/vclvcstc/r/m/ttsk/dtn/ttskdtn_chitiet?dDocName=MOF1573 09\&dID=80566\&_afrLoop=32318272725741412\#!\%40\%40\%3FdID\%3D80566\%26_afrLoop\%3D323182727 25741412\%26dDocName\%3DMOF157309\%26_adf.ctrl-state\%3Dzl42p99wj_4.

[3] TCVN IEC/ISO 31010:2013. Quản lý rủi ro - Kỹ thuật đánh giá rủi ro.

[4] McDermott, R., Mikulak, R. J., và Beauregard, M. (2008). The basics of FMEA. CRC Press. 
[5] Liu, L., và Ding, Y. (2014). Supply chain management risks in a sushi restaurant. University of Galve. Available: http://www.diva-portal.org/smash/get/diva2:698252/FULLTEXT01.pdf

[6] Palaniappan, P. K. (2014). Risk Assessment and Management in Supply Chain. Global Journal of Research In Engineering, 14(2)

Available: https://globaljournals.org/GJRE_Volume14/3-Risk-Assessment-and-Management.pdf

Ngày nhận bài: 23/07/2019

Ngày chấp nhận đăng: 28/11/2019 